\title{
Oxidative Stress and Male Infertility: Evidence From a Research Perspective
}

\begin{abstract}
Bashir Ayad 1,2, Temidayo S. Omolaoye ${ }^{31}$, Nicola Louw ${ }^{2}$, Yashthi Ramsunder ${ }^{2}$, Bongekile T. Skosana ${ }^{2}$, Peter I. Oyeipo ${ }^{2,4}$ and Stefan S. Du Plessis ${ }^{2,3 * t}$
\end{abstract}

1 Department of Physiology, Faculty of Medicine, Misurata University, Misrata, Libya, ${ }^{2}$ Division of Medical Physiology, Faculty of Medicine and Health Sciences, Stellenbosch University, Tygerberg, South Africa, ${ }^{3}$ Department of Basic Medical Sciences, Mohammed Bin Rashid University of Medicine and Health Sciences, Dubai, United Arab Emirates, ${ }^{4}$ Department of Physiology, College of Health Sciences, Osun State University, Osogbo, Nigeria

Male fertility potential can be influenced by a variety of conditions that frequently coincide. Spermatozoa are particularly susceptible to oxidative damage due to their limited antioxidant capacity and cell membrane rich in polyunsaturated fatty acids (PUFAs). The role of oxidative stress (OS) in the etiology of male infertility has been the primary focus of our Stellenbosch University Reproductive Research Group (SURRG) over the last 10 years. This review aims to provide a novel insight into the impact of OS on spermatozoa and male reproductive function by reviewing the OS-related findings from a wide variety of studies conducted in our laboratory, along with those emerging from other investigators. We will provide a concise overview of the production of reactive oxygen species (ROS) and the development of OS in the male reproductive tract along with the physiological and pathological effects thereof on male reproductive functions. Recent advances in methods and techniques used for the assessment of OS will also be highlighted. We will furthermore consider the current evidence regarding the association between OS and ejaculatory abstinence period, as well as the potential mechanisms involved in the pathophysiology of various systemic diseases such as obesity, insulin resistance, hypertension, and certain mental health disorders which have been shown to cause OS induced male infertility. Finally, special emphasis will be placed on the potential for transferring and incorporating research findings emanating from different experimental studies into clinical practice.

Keywords: oxidative stress, male infertility, semen analysis, obesity, hypertension, diabetes mellitus

\section{INTRODUCTION}

Infertility is one of the most complicated disorders of the reproductive system. It is characterized by the inability to conceive after 1 year or longer of regular unprotected sexual intercourse (1). Worldwide, about $8-12 \%$ of couples of reproductive age have been reported to be affected by infertility, with a widely divergent estimates of prevalence across regions and countries (2). Usually, when the attributable causes of female infertility have been eliminated and/or semen analysis results fail to meet the World Health Organization (WHO) criteria (3), male factor infertility is taken into consideration as the potential etiological factor. Males are considered to be the sole cause of infertility in almost $20 \%$ of all cases and are at least partly involved in another $30-40 \%$ (4). Despite remarkable advances in the diagnosis and management of male infertility, almost one half of all cases still idiopathic, for which no evident etiological factor has been identified (5). 
In recent years, an emerging concern has been raised regarding the overall increase in male infertility rates, reflecting a global time-related deterioration in semen quality with concomitant increase in the incidence of male reproductive abnormalities (6-9). Although the particular reason for the increased incidence of male infertility remains elusive, various environmental, nutritional and socioeconomic factors have been suggested to contribute to the downward trend in semen quality $(10,11)$. Furthermore, common complications including obesity, dyslipidaemia, hypertension, insulin resistance as well as psychological stress and anxiety have also been associated with impaired fertility in males of reproductive potential (1214). The link between these comorbidities and male infertility appears to be complicated and poorly understood. However, these is research-based evidence demonstrating that oxidative damage is one of the fundamental mechanisms involved in the etiopathogenesis of these illnesses (15-20). Concurrently, the critical role of oxidative stress (OS) in the development of male reproductive dysfunction has continued to gain a great deal of attention (21-24).

Redox equilibrium is essential for maintaining various vital aspects of sperm functionality. However, an imbalance in the generation and elimination of reactive oxygen species (ROS) negatively affects sperm quality due to oxidative damage (25). Owing to their imperfect antioxidant capacity and cell membrane rich in polyunsaturated fatty acids (PUFAs), spermatozoa are especially vulnerable to oxidative destruction. Under certain pathological conditions, ROS can be converted into highly reactive agents, causing dysregulation of various cellular signaling pathways and extensive damage to multiple biomolecules including nucleic acids, proteins, and lipids. The subsequent series of adverse events includes loss of membrane integrity, mitochondrial dysfunction, impaired sperm motility as well as DNA damage and apoptosis $(23,26)$.

The role of OS in the etiology of male infertility has been the primary focus of our Stellenbosch University Reproductive Research Group (SURRG) over the last 10 years. This review aims to provide a novel insight into the impact of OS on spermatozoa and male reproductive function by reviewing the OS-related findings from a wide variety of studies conducted in our laboratory, along with those emerging from other investigators. We will provide a concise overview of the production of ROS and the development of OS in the male reproductive tract along with the physiological and pathological effects thereof on male reproductive functions. Well-known and recent advances in methods and techniques used for the assessment of OS will also be highlighted. We will furthermore consider the current evidence regarding the association between OS and ejaculatory abstinence period, as well as the potential mechanisms involved in the pathophysiology of various systemic diseases such as obesity, insulin resistance, hypertension, and certain mental health disorders which have been shown to cause OS induced male infertility. Finally, special emphasis will be placed on the potential for transferring and incorporating research findings emanating from different experimental studies into clinical practice.

\section{CURRENT APPROACHES AND METHODS IN THE ASSESSMENT OF OS MARKERS IN SPERM AND SEMEN}

There are several methods to measure ROS in the laboratory setting. These include: the the indirect measurement of via enzymatic antioxidant levels (CAT), superoxide dismutase (SOD), glutathione peroxidase (GPx), reduced glutathione (GSH) and Thiobarbituric Acid Reactive Substances (TBARS) via by means of spectrophotometric measurement; the direct measurement of total antioxidant capacity (TAC) via Mioxys; the use of chemiluminescence to detect ROS species via the membrane permeable reagent, luminol; and the assessment of ROS and reactive nitrogen species (RNS) molecules via florescent markers (27) which can be measured via using e.g., flow cytometry and fluorescence microscopy.

Seminal plasma is well-endowed with various ROS and thus the TAC of sperm is an example of an indirect method of assessing ROS $(28,29)$. Antioxidant enzymes such as CAT, SOD, GSH and GPx represent the TAC of sperm (29), and low levels have been discovered in males with impeded fertility (29). Several reagents are used per assay in order to measure the activity of these antioxidant enzymes.

\section{Superoxide Dismutase}

- The SOD enzyme assay is dependent on the spectrophotometric assessment of superoxide $\left(\mathrm{O}_{2}^{-\bullet}\right)$.

- The assay uses two chemicals, 6 hydroxydopamine $(6 \mathrm{HD})$ and diethylenetriaminepentaacetic acid (DETAPAC), to generate $\mathrm{O}_{2}^{-\bullet}$ anions, which are reduced in the presence of SOD.

- The reaction yields a colorimetric signal where samples with reduced amounts of SOD emit a lesser signal that can be measured via colorimetry (30).

\section{Catalase}

- CAT is quantified by adding hydrogen peroxide $\left(\mathrm{H}_{2} \mathrm{O}_{2}\right)$ to the sample and analyzing the rate of decomposition of CAT, which is proportional to a reduction in the absorbance reading generated by the instrument $(29,31)$.

\section{Reduced Glutathione}

- GSH can be determined by adding 5,5'-dithiobis-2nitrobenzoic acid (Ellman's reagent) to the sample.

- This reagent reacts with the thiol groups of GSH which convert 2-nitro-5-thiobenzoate $\left(\mathrm{NTB}^{-}\right)$to $\mathrm{NTB}^{2-}$, thereby producing a yellow color, which can subsequently be quantified (29).

\section{Glutathione Peroxidase}

- GPx is measured by adding glutathione reductase (GR) to the sample after which nicotinamide adenine dinucleotide phosphate (NADPH) is transformed to a reduced state, allowing a decrease in absorbance to be subsequently measured $(30,32)$.

\section{Lipid Peroxidation}

- OS leads to cellular injury via several mechanisms, with lipid peroxidation being a prominent one. Malondialdehyde 
(MDA) is a typical product of lipid peroxidation. Polyunsaturated fats yield lipid peroxides, which, due to their instability, disintegrate into several compounds including reactive carbonyl compounds, e.g., MDA. In addition, biological specimens undergoing OS contain TBARS such as aldehydes and hydroperoxides, which increase with increasing OS. MDA forms adducts with TBARS, thiobarbituric acid in particular, with which it forms a 1:2 adduct. This MDA-TBA complex, forming under acidic, high temperature $\left(90-100^{\circ} \mathrm{C}\right)$ conditions, elicits a colorimetric reaction.

- Additionally, 4-hydroxy-nonenal (HNE) and Isoprostanes (F2-isoprostane, 15-(S)-8-isoprostagladin F2 $\alpha$ ) are byproducts of PUFA, and are also considered as indices of lipid peroxidation $(33,34)$. These products can be measured via enzyme-linked immunosorbent assay (ELISA), gas chromatography mass spectrometry (GC-MS) or by liquid chromatography- mass spectrometry (LC-MS) (35).

\section{Total Antioxidant Capacity}

- TAC highlights the crucial role of antioxidant enzymes in counterbalancing ROS generation and therefore can be a powerful tool in determining the redox status of a sample (36). However, the measurement of individual antioxidant enzymes can be time consuming and costly. Additionally, it does not generate a direct measure of the total level of ROS in a system (37).

\section{Oxidative Reduction Potential}

- Oxidative reduction potential (ORP) is a direct analysis of OS (38). It measures the transfer of electrons from a reductant to an oxidant (38).

- ORP has been shown to be negatively correlated with sperm concentration and total sperm count (38).

- This analysis does not rely on any biomarker for OS and allows for the quantification of all oxidants and antioxidants in a given sample (38).

- The Male infertility Oxidation System (MiOXSYS) can be used to accurately measure ORP (39).

- The system consists of an electrochemical cell with a counter and a reference electrode, as well as an impedance electrometer (39).

- It measures static ORP (sORP) which is indicative of the existing balance between total oxidants and reductants in a sample, and the antioxidant capacity reserve (cORP). Samples of high sORP levels indicate an imbalance that suggests the presence of OS (39).

- Unlike chemiluminescence (see later) where ROS levels have a significantly short half-life, ORP measurements are stable for up to $120 \mathrm{~min}$.

- Additionally, MiOXSYS sORP's ability to measure all oxidants and reductants makes it clinically meaningful in the diagnosis of cases of male infertility that is associated with high ROS levels (40).

\section{Chemiluminescence}

- Chemiluminescence measures light that is emitted in a reaction when reagents are added to a biological sample (41).
- Membrane permeable probes such as luminol and lucigen react with $\mathrm{ROS}$ and generate a luminescent signal. Luminol measures $\mathrm{H}_{2} \mathrm{O}_{2}, \mathrm{O}_{2}^{-\bullet}$ and other ROS as these oxidants bind to luminol and they become univalently oxidized luminol radicals, or an oxidative event occurs which can be measured by a chemiluminometer.

- The oxidative event is a one-electron reaction which occurs due to the presence of e.g., endogenous $\mathrm{H}_{2} \mathrm{O}_{2}$ peroxidase.

- Unstable radicals are generated which react with oxygen molecules in their ground state, producing $\mathrm{O}_{2}^{-\bullet}$. The $\mathrm{O}_{2}^{-\bullet}$ additionally oxygenates luminol radical species, which then creates an unstabe endoperoxide that degrades and causes a light emission (41).

- Luminol and Lucigen are two probes that are used in chemiluminescent assays to detect ROS. Lucigenin is best suited to detect $\mathrm{O}_{2}^{-\bullet}$ as it is positively charged, which renders it membrane-impermeable and allows it to react with $\mathrm{O}_{2}^{-\bullet}$ in the extracellular space $(29,42)$. Unlike Lucigen, Luminol is uncharged and is therefore membrane permeable. This allows it to react with ROS in both the intra and extracellular spaces (29). Luminol reacts with a variety of ROS including $\mathrm{O}_{2}^{-\bullet}$, $\mathrm{H}_{2} \mathrm{O}_{2}$ and hydroxyl radicals $\left(\mathrm{OH}^{\bullet}\right)$ (40). This probe, however, is unable to differentiate between the types of ROS (40).

- Chemiluminescent assays have been used to show a negative association between an increase in ROS levels and sperm parameters. These parameters include sperm motility, viability, morphology and concentration (29). A variety of factors may influence the data generated by the chemiluminescence assays, which include: the presence of leukocytes in the sperm sample, sperm incubation time, the $\mathrm{pH}$, and contamination of the seminal plasma. It should also be noted that both sample and probe concentrations also affect luminescence, thus it is important to have a fixed probe concentration for varying concentrations of sperm.

- Chemiluminescence assays are sensitive, which is ideal as sperm generally produce low concentrations of ROS $(40,43)$. The results of the assay may be reliable in samples with sperm of a concentration \pm 1 million/mL, as the sensitivity of the assay declines significantly at greater concentrations (44).

\section{Flow Cytometry}

- Flow cytometry involves the use of florescent markers to measure ROS and RNS $(45,46)$. Contradictory to chemiluminescence, florescent techniques have a higher accuracy, specificity and reproducibility rate.

- Flow cytometry allows for the exclusive focus on spermatozoa (46). Additionally, a large number of cells can be analyzed at once.

- However, the utilization of florescent probes requires expensive equipment. The data generated does not quantify ROS but rather is indicative of the percentage of cells displaying a high ROS activity.

- A florescent probe like 2,7-dichlorofluorescein diacetate $\left(\mathrm{H}_{2}\right.$ DCFDA) penetrates the spermatozoa and indicates $\mathrm{H}_{2} \mathrm{O}_{2}$ concentrations, as $\mathrm{H}_{2} \mathrm{O}_{2}$ de-esterifies in the presence of DCFH and forms fluorescent 2,7-dichlorofluorescein (DCF) (47). DCF fluoresces and this can be measured. 
- Dihydroethidium/hydroethidine (DHE) is a non-florescent probe that is oxidized by a variety of reactive oxygen and nitrogen species. This probe is primarily used to visualize $\mathrm{O}_{2}^{-\bullet}$ production. The probe allows for hydroxylation which generates a red florescent emission that, in turn, stains the mitochondrial and nuclear DNA of sperm. Utilizing DHE is advantageous as it allows for a clearer insight into the frontier role of the mitochondria in ROS production (48).

\section{ORIGINS OF ROS IN SEMEN}

Leukocytes often exist throughout the male genital tract and the presence of small quantities in the ejaculate represents a normal finding. However, when the level of the peroxidasepositive leukocytes goes beyond $1 \times 10^{6} / \mathrm{mL}$, leukocytospermia is present (3). Polymorphonuclear neutrophils, the most common type of seminal leukocytes, represent a primary endogenous source of ROS in semen. Stimulation of these leukocytes during an accessory gland or genitourinary infections triggers a prominent increase in oxygen consumption and ROS generation $(49,50)$, which impose OS on the engulfed pathogens as part of the defense mechanisms. In patients with genital tract infection, the presence of elevated levels of leukocytes in semen has been associated with suboptimal semen quality and impaired fertility potential (51-54). Several hypotheses have been suggested to elucidate the role of leukocytospermia in enhancing the generation of ROS by human spermatozoa, but the precise molecular mechanism remains unclear. However, the direct sperm-leukocyte interaction, as well as the inflammatory mediators released by infiltrating leukocytes and bacteria have been proposed to be implicated in altering the aerobic metabolism of spermatozoa $(55,56)$. Furthermore, the presence of bacteria in semen has been suggested to attenuate the ROS scavenging capacity of spermatozoa. Such effect may vary widely depending on the virulence of the pathogen as well as the sperm subpopulation $(56,57)$.

Additionally, spermatozoa with excess residual cytoplasm retaining along the midpiece are considered immature and functionally defected cells. Cytoplasmic residues contain an increased amount of enzymes particularly glucose-6-phosphate dehydrogenase (G6PD) and NADPH oxidase (25). The excessive presence of G6PD results in the generation of a significant amounts of NADPH, which represents a primary source of electrons essential for the reduction of molecular oxygen to $\mathrm{O}_{2}^{-\bullet}(50)$.

Mature spermatozoa themselves have also been suggested to play a critical role in the production of ROS, probably as an end-product of cellular metabolism (26). Mitochondria play a key role in the synthesis of ROS via the activation of the electron transport mechanism at the inner surface of the mitochondrial membrane during oxidative phosphorylation process. This crucial cellular process involves the transfer of electrons and the reduction of oxygen molecules, producing $\mathrm{O}_{2}^{-}$(58). Furthermore, mitochondrial membranes are highly rich in PUFAs which are primary substrates for ROS attack and lipid peroxidation. This concurrently triggers the production of highly reactive lipid aldehydes which covalently interact with electron transport chain proteins, initiating vicious cycles of increased rates of mitochondrial ROS generation (59).

Another source of OS is a varicocele testis. Varicocele is an abnormal distention of the testicular veins in the pampiniform plexus within the spermatic cord. Clinical varicocele is a major contributor to male infertility, affecting as many as $40 \%$ of men with primary infertility and up to $80 \%$ of men with secondary infertility (60-62). There is considerable evidence that suggest the implication of OS in the underlying mechanism of infertility in varicocele patients. Numerous studies have reported significantly increased levels of ROS in the semen of varicocele patients (6365). Varicocele patients have further shown considerably elevated levels of 8-hydroxy-2'- deoxyguanosine, which is a sensitive biomarker of oxidative DNA damage (66). These findings are supported by the recent evidence highlighting the effectiveness of varicocelectomy in improving sperm motility, DNA integrity, antioxidant capacity and pregnancy rates (67-70) in infertile men with varicocele.

Besides the above-mentioned endogenous sources of ROS, a growing list of potential lifestyles and environmental factors have been suggested to contribute to the extreme generation of ROS in semen. These include cigarette smoking (71), alcohol consumption (72) and electromagnetic radiations (73).

\section{PHYSIOLOGICAL ROLES OF ROS}

During spermatogenesis and epididymal transit, appropriate amounts of ROS are required for the oxidation of cystein-thiol groups essential for chromatin compaction and stabilization in spermatozoa (25). As shown in Figure 1A, ROS are furthermore implicated in the production of the mitochondrial capsule through the oxidation of protein thiols catalyzed by phospholipid hydroperoxide glutathione peroxidise. This enzyme is finally converted to a cross-linked structural protein, comprising a significant component of the mitochondrial sheath of mature spermatozoa $(26,74)$.

Hyperactivation is a sperm motility pattern characterized by an extremely vigorous whiplash-like flagellar beating, which enhances the ability of the sperm to penetrate the cumulus cell layer surrounding the oocyte $(75,76)$. The exact molecular mechanism underlying sperm hyperactivation has not been fully elucidated. However, a mild, constant generation of $\mathrm{O}_{2}^{-\bullet}$ has been shown to be crucial not only for the initiation, but also the preservation of the hyperactivated state (75). Furthermore, a significant increase in the proportion of spermatozoa displaying hyperactivated motility was observed when the incubation medium had been supplemented with an optimum concentration of $\mathrm{H}_{2} \mathrm{O}_{2}$ (77).

Capacitation is a crucial physiological process of sperm maturation occurs during its passage through the female reproductive tract to enable sperm-oocyte interaction (78). During this process, ROS act as essential intracellular messengers to activate downstream signaling molecules mediating significant changes in the membrane architecture (i.e., membrane destabilization, permeability and lipid redistribution), which are prerequisite for successful fertilization (79). Furthermore, the established role of ROS in modulating tyrosine phosphorylation during capacitation and other relevant processes is tightly 


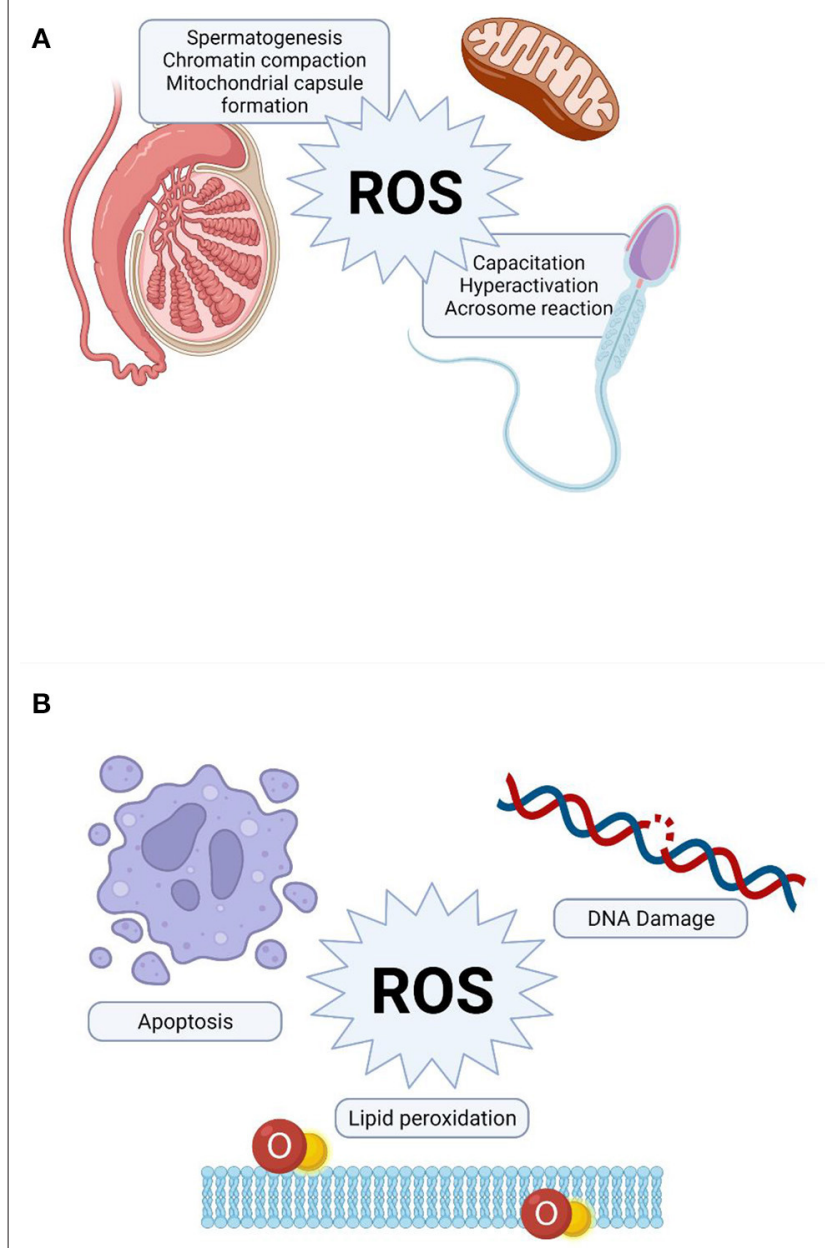

FIGURE 1 | Role of reactive oxygen species (ROS) in sperm function. (A) Physiological role of ROS, (B) Pathological effect of ROS on sperm function.

regulated by complex cross-talks between various signaling pathways, including the cAMP/PKA and the extracellular signal-regulated kinase pathways (79-81).

In contrast to sperm capacitation, acrosome reaction is an irreversible process which involves the release of acrosomal hydrolytic enzymes to attain sperm oocyte fusion (82). In vivo, the sperm-zona pellucida binding triggers a cascade of signal transduction reactions that culminates in an significant increase in intracellular $\mathrm{Ca}^{2+}$ levels required for acrosomal exocytosis (83). The generation of both $\mathrm{O}_{2}^{-\bullet}$ and $\mathrm{H}_{2} \mathrm{O}_{2}$ within physiological limits is essential to elicit acrosome reaction through the activation of tyrosine phosphorylation of potential target proteins particularly on the pre-equatorial region of the sperm head surface (84). The biochemical cascade of events involved in triggering the acrosome reaction appears to share some underlying features with those identified for capacitation, such as $\mathrm{Ca}^{2+}$ influx and the activation of adenylate cyclase and cAMP as well as the phosphorylation of reasonably similar target substrates $(25,81,85)$.

\section{PATHOLOGICAL EFFECTS OF ROS ON SPERMATOZOA}

Remarkably increased ROS levels have been detected in 25$40 \%$ of semen samples of infertile patients $(28,86,87)$. The extent of oxidative damage to spermatozoa may vary significantly among infertile men depending on the concentrations and properties of reactive molecules, length of exposure, antioxidant efficiency as well as surrounding temperature and oxygen tension. High concentrations and prolonged exposure to ROS causes extensive damage to various integral cellular biomolecules (Figure 1B), including proteins, lipids and nucleic acids, which ultimately hampers multiple cellular functions $(25,26,49,88)$.

Sperm plasma membrane contains larger amounts of PUFAs, particularly docosahexaenoic acids, which are required to maintain optimal fluidity essential for multiple membrane fusion events. However, theses fatty acids act as potential substrates for peroxidation as they comprise methylene groups with highly reactive hydrogen atoms, thereby enhancing the susceptibility of sperm to oxidative damage (89). Lipid peroxidation is a chain reaction initiated when ROS, particularly $\mathrm{OH}^{\bullet}$ and Hydroperoxyl $\left(\mathrm{HO}_{2}\right)$ generated from $\mathrm{O}_{2}^{-\bullet}$, combine with a hydrogen atom from a fatty acid to produce a lipid radical. These unstable radicals react rapidly with oxygen molecules to form peroxy fatty acid radicals, which are thereafter converted into lipid peroxides. In the presence of a transitional metal ion, lipid peroxide is catalyzed into $\mathrm{OH}^{\bullet}(90)$, which have the ability to attract electrons from other PUFAs to generate new radicals and thereby propagating the lipid peroxidation chain reaction (25). This chain reaction is halted when the radicals react with each other to create a non-reactive product called MDA. This by-product is widely used as a biomarker to estimate the extent of peroxidation damage to spermatozoa (91). Another product of interest in the assessment of lipid peroxidation in any biological sample are the Isoprostanes (IsoPs).

The sustained lipid peroxidation chain reaction results in progressive loss of membrane fatty acids, with consequent decrease in membrane fluidity, increased non-specific permeability to ions, and inhibition of membrane bound receptors and enzymes (23).

Besides their role in mediating lipid peroxidation, ROS especially nitric oxide $\left(\mathrm{NO}^{\bullet}\right), \mathrm{O}_{2}^{-\bullet}$ and $\mathrm{OH}^{\bullet}$ (92), have also been shown to attach to sperm DNA molecules causing excessive modifications and deletions in their nucleotide bases and strand breakages, along with other multiple genotoxic effects (93). Sperm DNA is especially prone to oxidative damage owing to its poor chromatin compaction and incomplete protamination $(55,94)$. The role of ROS in sperm DNA damaging has further been supported by the significant and positive correlations observed between the levels seminal ROS and the proportions of spermatozoa with fragmented DNA $(95,96)$.

ROS has also been implicated as an apoptotic stimulus that triggers the mitochondria to release some signaling molecules crucial for the activation of programmed cell death (97). Mature spermatozoa from ROS-positive infertile patients showed substantially elevated levels of apoptosis compared with the 
control group (98). However, antioxidant therapy has recently shown to reduce the apoptotic response to OS (99).

\section{OS-INDUCED CHANGES IN CONVENTIONAL SEMEN PARAMETERS}

Several studies have been undertaken correlating various OS markers with fertility status (100-102) and also basic sperm quality parameters including morphology $(103,104)$ and motility $(24,105,106)$. In this regard, the SURRG has published the most recent and comprehensive study aiming at establishing statistical correlations between conventional semen parameters obtained with Computer-aided sperm analysis (CASA) and a set of OS and membrane lipid peroxidation variables. The insight gained from this study complement those of previous investigations and contribute additional evidence with respect to the significance of detailed CASA motility, velocity and kinematic parameters in bridging the gap between conventional semen analysis and the oxidative status (107). Results obtained from this study indicates that rapid progressive motility should prove to be particularly valuable sensitive indicator of lipid peroxidation that could be impaired prior to any detectable deterioration in other sperm motion characteristics. In addition, the observed inverse relationship between intracellular sperm $\mathrm{O}_{2}^{-\bullet}$ levels and average-path velocity (VAP) is important in furthering our understanding of the possible role of free radicals in constraining the actual rate of sperm forward movement within the female reproductive tract, which is vital for successful fertilization. Similarly, the strong positive correlations between SOD activity and both curvilinear velocity (VCL) and amplitude of lateral head displacement (ALH) established a quantitative framework for detecting the role of OS in the development of spontaneous and premature hyperactivated motility of spermatozoa in the ejaculate.

Continuing along these lines, it is recommended for future studies the predicting of OS markers from conventional basic parameters through the building of linear regression models assist in indicating the extent to which changes in each individual measurement of basic semen analysis are related to changes in the oxidative status. Indeed, OS markers provide valuable clinical insight into vital aspects of sperm functions. However, the prediction of these markers from the core basic parameters could possibly assist in limiting the necessity for these assays, which are complex, highly expensive and lack universal standardization. This would also enhance the applicability of basic semen analysis, which remains the bedrock of any semen diagnosis, as a more cost-effective and efficient approach for the diagnosis of idiopathic and unexplained male infertility.

\section{ALTERATIONS IN OS STATUS DURING DIFFERENT SEXUAL ABSTINENCE PERIODS}

According to the most recent WHO manual for processing and examining human semen (108) and guidelines for the same by other associations such as Nordic Association for Andrology (NAFA) and the European Society of Human Reproduction and Embryology (ESHRE) (109), subjects must remain abstinent for a minimum period of 2 days, but not longer than seven days before collecting a sample for a standard semen analysis. While the NAFA and ESHRE further added that abstinence intervals of 3-4 days is preferred for analyzing human semen. These variations in ejaculatory abstinence periods suggested by different regulatory bodies has instigated a growing concern as to what the precise period of ejaculatory abstinence ought to be for an optimal semen sample. This has prompted several studies to examine the influence of abstinence periods on various semen quality parameters; however, the results are not conclusive.

Given the gap of evidence, members of our SURRG recently published a comprehensive systematic review of literature assessing the relationship between sexual abstinence and a range of semen/sperm quality parameters (110). This review included a total of 30 studies published between January 1979 and December 2016, where the periods of sexual abstinence were categorized into $\leq 1$ day, $2-3$ days, $4-5$ days, $6-7$ days and $>7$ days. Ayad et al. displayed that three studies had considered intracellular ROS concentration as a quality parameter of sperm when evaluating the effect of the abstinence period $(38,111,112)$, whereas only one study investigated the relationship with respect to seminal ROS levels (113). These studies collectively showed a general trend of decrease in ROS levels after short abstinence compared with long abstinence. Additionally, only one study (114) had evaluated the relationship in terms of seminal plasma antioxidants and sperm lipid peroxidation. Marshburn et al. reported a considerable improvement in the TAC of seminal plasma after 1 day of sexual abstinence compared to 4 days, whereas lipid peroxidation of the sperm membrane remained unchanged. Furthermore, a study conducted in our laboratory included a hundred normospermic individuals revealed that only $4 \mathrm{~h}$ of sexual abstinence could significant increase seminal plasma SOD activity, but did not change the CAT activity or TBARS levels (115). More recently, shortening the abstinence duration from $>4$ to $\leq 2$ days resulted in a significant reduction in the levels of ROS in semen samples collected from 90 patients with unexplained male factor infertility (116). Similar findings were also shown by Okada et al. (117), who collected semen samples from 50 normospermic men each abstaining sequentially for 1 and 4 days. They reported a significant decline in seminal plasma TBARS levels and intracellular oxidative activity after only 1 day of sexual abstinence (117).

Despite the limited data available, the weight of evidence indicates that decreasing the ejaculatory abstinence period may minimize the adverse effects of OS on sperm quality and function. In addition to their limited intracellular antioxidant capacity spermatozoa, during their epididymis maturation and storage, are constantly exposed to ROS damage by lipid peroxidation through their PUFA rich plasma membranes. Accordingly, the release of spermatozoa through more frequent ejaculations might be a potential strategy to attenuate the detrimental effects of ROS and improve perm quality (Figure 2) (115, 118). 


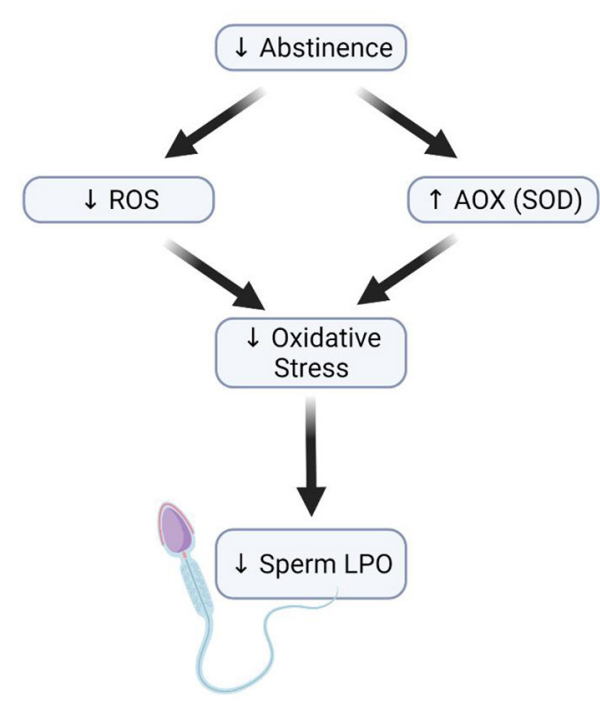

FIGURE 2 | Effect of short abstinence on sperm function. Decrease in the length of abstinence (short abstinence) leads to a reduction in ROS levels and an increased antioxidant level, which consequently reduces the rate of sperm membrane lipid peroxidation.

\section{HYPERTENSION-INDUCED OS IN MALE INFERTILITY}

Hypertension, also referred to as elevated blood pressure is estimated to affect about 1.28 billion adults aged $30-79$ globally (119), indicating that $16.4 \%$ of the world's population is hypertensive. Studies have associated hypertension to some aspects of sperm function (120-123). A group from Brazil that utilized a rat model for renovascular hypertension to investigate the link between hypertension and male infertility observed a decreased sexual behavior and impaired spermatogenesis, which was attributed to imbalances in prolactin, testosterone and follicle-stimulating hormone (FSH) levels (122). Additionally, a group from Italy found elevated levels of clusterin, a glycoprotein linked with abnormal sperm morphology, in a cohort of hypertensive men when compared to normotensive men (123). In the United States, Guo et al. investigated the association between hypertension and semen quality (121). They reported that men with hypertension have one or more semen abnormalities (reduced semen volume ( 2.1 vs. $3.0 \mathrm{~mL}, p<0.001$ ), sperm motility ( 41.0 vs. $47.0 \%, p=0.008$ ), total sperm count (103.8 vs. $147.0, p=0.005)$ and total motile sperm count (43.1 vs. $65.9, p=0.003$ ) compared to normotensive men.

Kasman et al. investigated whether the association between male infertility and occurrence of cardiometabolic disease (diabetes, hypertension, hyperlipidemia, and heart disease) is modified by socioeconomics, race, or geographic region (16). They reported that infertile men had a higher risk of incident for hypertension, diabetes, hyperlipidemia, and heart disease regardless of race, region or socioeconomic status. The prevalence and effects of medical comorbidities (hypertension, hyperlipidemia, hyperuricemia and skin disease) on spermatogenesis was determined by Shiraishi and Matsuyama (124) in a group of fertile and infertile men. The prevalence of comorbidities was significantly higher in the infertile men (21.7\%) than in the fertile men (9.1\%), particularly for hypertension (17.8\%), hyperlipidemia (5.9\%), hyperuricemia (5.2\%), and skin disease (3.0\%). Among the infertile men, the reproductive functions were abnormal in the men with comorbidity compared with those without comorbidity. The authors concluded that medical comorbidities are associated with impaired sperm production and suggested that male infertility evaluation offers not only specific therapy to improve semen parameters but also treatment for non-specific medical comorbidities, which may benefit general health status and spermatogenesis restoration. Several other population-based studies have shown the association between male infertility and hypertension (125-127). Animal studies have also thrived in this aspect of reproductive research and have provided evidence that hypertension is associated to male infertility (128130). Akinyemi et al. reported a significant decrease in serum total testosterone and reduced sperm progressive motility in hypertensive rats. They showed increased OS status in the testes and epididymides of hypertensive rats as evidenced by a significant reduction in total and non-protein thiol levels, glutathione S-transferase (GST) activity with a concomitant increase in DFCH oxidation and TBARS production. Likewise, a decreased testicular and epididymal $\mathrm{NO}^{\bullet}$ level with simultaneous elevation in arginase activity was observed in hypertensive rats (128). One of the studies performed in the SURRG laboratory also investigated the association between obesityinduced hypertension and male infertility. Obese hypertensive rats presented with significantly increased levels of serum inflammatory cytokine including, IL-1 $\beta$, IL-6, IL-12, IL-18 and TNF- $\alpha$, when compared to the lean group. Also observed were histopathological testicular changes, as there were significant reductions in the seminiferous tubule area $(97,807 \pm 1,488$ $\mu \mathrm{m}^{2}$ vs. $\left.118,347 \pm 6,073 \mu \mathrm{m}^{2}, p<0.05\right)$, seminiferous tubule diameter $(354.0 \pm 3.0 \mu \mathrm{m}$ vs. $386.2 \pm 9.5 \mu \mathrm{m}, p<0.05)$, lumen area $\left(19,891 \pm 1,717 \mu \mathrm{m}^{2}\right.$ vs. $\left.30,058 \pm 3,639 \mu \mathrm{m}^{2}, p<0.01\right)$, and lumen diameter $(157.8 \pm 7.3 \mu \mathrm{m}$ vs. $191.2 \pm 12.2 \mu \mathrm{m}$, $p<0.05)$ in the obese hypertensive group compared to the lean group. The obese hypertensive rats also presented with a significantly reduced testosterone: estradiol ratio (130). Another study performed with a hypertensive rat model reported altered sperm quality (sperm motility, normal morphology, sperm count) in hypertensive rats (129). Their findings also showed a reduction in $3 \beta$ and $17 \beta$-hydroxysteroid hydrogenase $(3 \beta$-HSD and $17 \beta-\mathrm{HSD}$ ) activities, as well as testosterone, luteinizing hormone (LH), and FSH levels. An increased ROS and MDA levels were observed with a subsequent decrease in thiol levels, CAT, and glutathione-S-transferase activities (129).

Deducing from the above findings, it can be suggested that hypertension impairs male fertility through (i) a reduction in blood flow to the testis, as the oxygen-dependent organ functions in a state of near anoxia, such a decrease in blood flow may very likely have profound effects on the tissue morphology that ultimately would predispose to various 


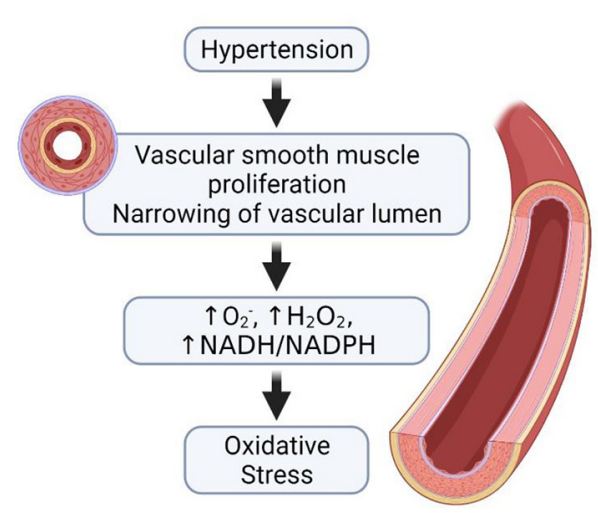

FIGURE 3 | Hypertension and the development of oxidative stress. In the occurrence of hypertension, there is proliferation of the vascular smooth muscles and the narrowing of vascular lumen. The narrowing of the vascular lumen leads to increase in the generation of ROS, thus causing oxidative stress.

forms of hypo-spermatogenesis with consequent compromise in reproductive capability, (ii) altered hormone levels, as the obstructed spermatogenic cells are unable to produce adequate hormone for normal spermatogenesis, (iii) increase in the formation of ROS and a subsequent decrease in antioxidant activities, which consequently lead to OS (Figure 3), and (iv) alteration in the expression of important glycoproteins necessary for normal testicular and sperm morphology.

\section{OBESITY-INDUCED OS IN MALE INFERTILITY}

Obesity ensues when there is an energy imbalance between the energy consumed and energy expended, therein leading to excessive accumulation of fat (131). Obesity is a multifactorial disorder influenced by genetic or environmental factors, and the incidence has tripled since 1975 as reported by the WHO (131). In 2016 , more than 1.9 billion adults of $\geq 18$ years old were overweight, of this, 650 million were obese, indicating that $39 \%$ of adults of the world's population aged $\geq 18$ were overweight $(39 \%$ of men and $40 \%$ of women) and $13 \%$ were obese (11\% of men and $15 \%$ of women) (131).

The consequence of obesity is not limited to the risk of developing cardiovascular diseases but also include the possibility of male fertility impairment (Figure 4). One of the review articles published by members of our lab explicitly explained how obesity has become a modern man's fertility nemesis (17), as it contributes to reduced semen quality, modified sperm proteomes, erectile dysfunction as well-cause other physical problems $(17,18)$.

Both animal and human studies have provided evidence that obesity indeed can impair male fertility (15, 132-136). One of the studies performed in the SURRG laboratory assessed the effect of long-term obesity on male reproductive functions (137). After inducing obesity in male Wistar rats for 54 and 60 weeks, respectively, sperm parameters and estradiol levels were adversely altered and some molecular modifications were observed. It was suggested that the instigator of the molecular and proteomic modifications includes an increase in the production of ROS, elevated stress proteins levels and higher levels of redox and inflammatory proteins. Further proteomic analysis of the epididymis and sperm revealed that proteins essential in metabolism, ROS production, stress, inflammation and in the regulation of reproductive function were adversely affected. This means that long term obesity may impair male fertility potential. This is in line with the findings of many others $(132,133)$. Another study showed that after feeding mice with a high-fat diet (HFD) for 8 weeks, there were manifestations of spermatogenic impairments such as decreased relative testicular weight, impaired testes morphology, and increased percentage of germ cell-depleted tubules. Sperm parameters and functions were also altered (sperm count, sperm motility, sperm viability, reduced serum testosterone), which consequently led to a decrease in pregnancy rate (132). The adverse effects seen were attributed to the occurrence of apoptosis, as there was an increase in caspase 3 activity and a decrease in Bcl-2 activity. Also observed in the obese mice were increased mRNA levels of Xbp1, Grp78 and CHOP, as these are indicators of endoplasmic reticulum stress, and are believed to be activated by obesity. Abbasihormozi et al. investigated the OS status in the semen samples of men with obesity and type 2 diabetes to validate whether OS in these diseases can influence fertility potential (15). The sperm motility, concentration, total sperm count, and normal sperm morphology were significantly reduced in obese men. The seminal plasma TAC was significantly reduced in the obese group with higher ROS levels, early apoptotic spermatozoa, and increased percentage of sperm with fragmented DNA. Also observed were decreased serum testosterone concentration and increased cortisol levels in the obese group. It was therefore concluded that increase ROS levels and elevated DNA fragmentation in men affected with obesity could be considered as prognostic factors in sub-fertile patients (15). The findings of the study of Abbasihormozi et al. is supported by Raad et al. who also reported impaired sperm quality of men with obesity (135).

Deshpande et al. investigated the effect of both diet-induced and genetically inherited obesity on male fertility in adult male rats. It was reported that the difference between HFDinduced obesity and genetically inherited obesity is shown in the expression of fertility-related hormones and spermatogenesis (138). The authors further explored the expression of genes related to reproductive hormone receptors, leptin signaling molecular biomarkers, pro-inflammatory cytokines, OS and cell cycle mediators in the testis (133). Their findings showed that both types of obesity have altered expression of hormone receptors, cytokines and biomarkers of OS, as well as cell cycle mediators; but the changes are different (133). The differences were seen in the metabolic pathways, and the changes are attributed to the variation in white adipose tissue accumulation (138).

Several other studies, both animal and human have highlighted that in obesity, there is excessive production of ROS, leading to OS and consequently induce apoptosis, which 


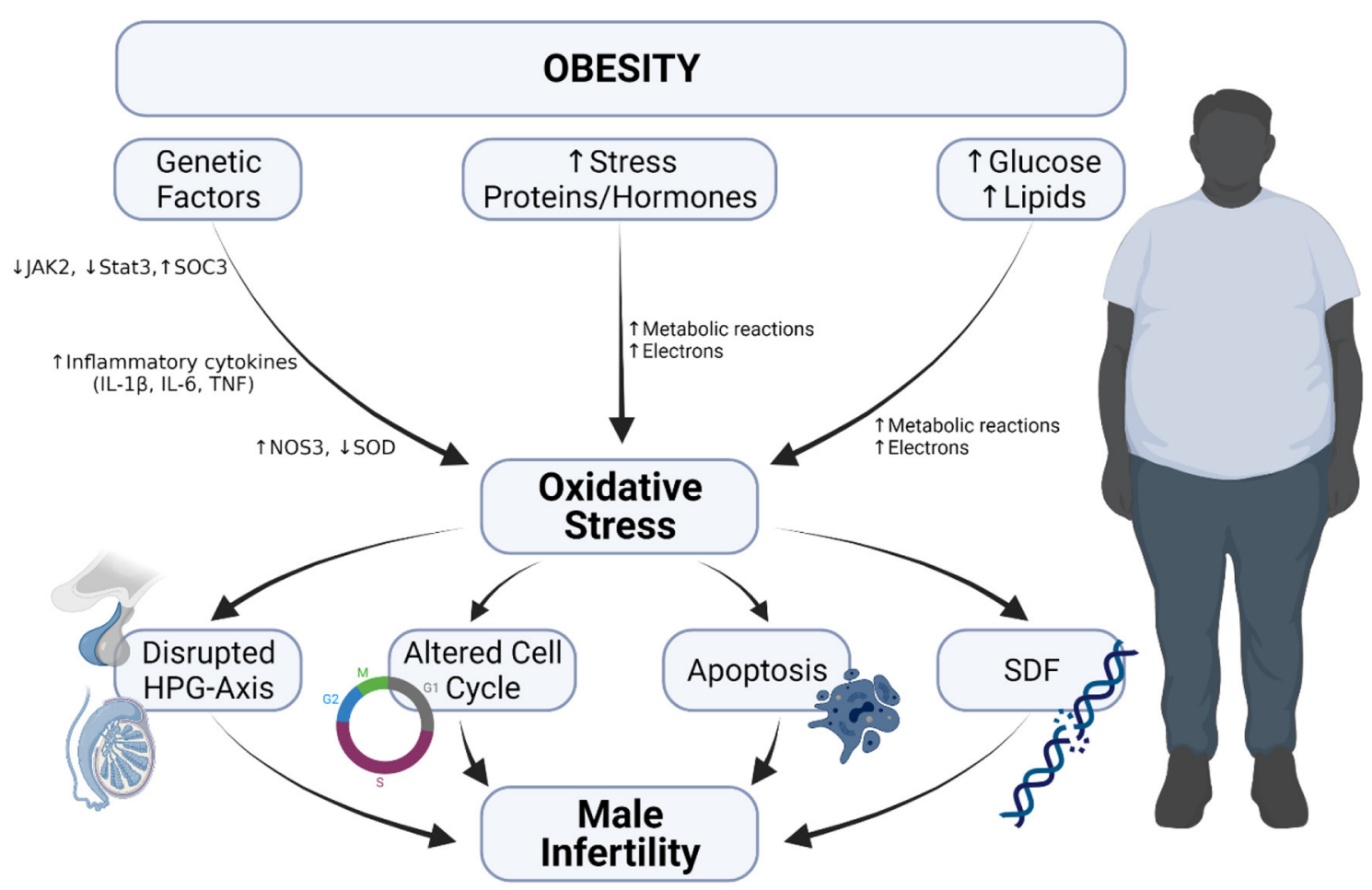

FIGURE 4 | Obesity-induced oxidative stress and male infertility. Obesity-induced oxidative occurs because of (i) increase in metabolic reaction due to elevated glucose and lipids levels, (ii) increase in the level of stress hormones and proteins and (iii) alteration in genetic composition. The occurrence of oxidative stress leads to disrupted hypothalamo-pituitary gonadal axis, induction of apoptosis, increased sperm DNA fragmentation and alters cell cycle, which cumulatively result in male infertility.

may further lead to reduced reproductive potential or subfertility (139-143). Some showed the disruption of the blood-testis barrier (141) in obesity, while some suggested that the duration have an unfavorable impact on male fertility $(142,143)$.

\section{DIABETES MELLITUS-INDUCED OS IN MALE INFERTILITY}

Hyperglycemia can occur because of the inability of the pancreatic beta cells to secrete insulin or as may arise from insulin resistance and variable degrees of inadequate insulin secretion resulting in diabetes and related comorbidities. Given that the global burden of diabetes is continuously increasing, it is estimated that the number of men in their reproductive age that will be affected with diabetes is likewise on the rise, as there is an elevation in the number of childhood and adolescent males with diabetes $(144,145)$.

Studies have shown that diabetes, both type I and type II induce subtle molecular changes that are essential for sperm quality and function. Bhattacharya et al. reported a significant decrease in sperm motility, including the number of rapid progressive spermatozoa (146). Another study revealed a significant reduction in sperm kinetic parameters and a decrease in the percentage of normal sperm morphology of male diabetic partners (147). Several other studies have also revealed a significant decrease in semen volume, sperm motility and morphology in the semen of diabetic men $(148,149)$ while some animal studies have equally reported alteration in sperm parameters (150-152). All these effects can partly be explained through the impact of OS, caused by the inequality between ROS production and antioxidant defense mechanisms (Figure 5) $(19,153)$. The process of how OS leads to male subfertility or infertility has been discussed in detail in the earlier section.

\section{PSYCHOLOGICAL DISORDERS AND OS IN MALE INFERTILITY}

The interaction between OS, male infertility and psychological disorders is interesting, as both fertility and the neural system are individually and collectively affected by OS. As mentioned, OS has been implicated as a significant contributor to male infertility (154). OS has independently been implicated in the pathogenesis of various disorders of the brain, such as anxiety disorders, depression, bipolar disorder and schizophrenia (155157). The contributing factor toward these pathologies is the presence of PUFAs within both the brain and spermatozoa, which are highly susceptible to damage by ROS. In the brain, its lipid-rich composition and extensive oxygen utilization (155157), amongst other factors, allow for significant susceptibility of the brain to OS-induced damage. The high rates of oxygen 


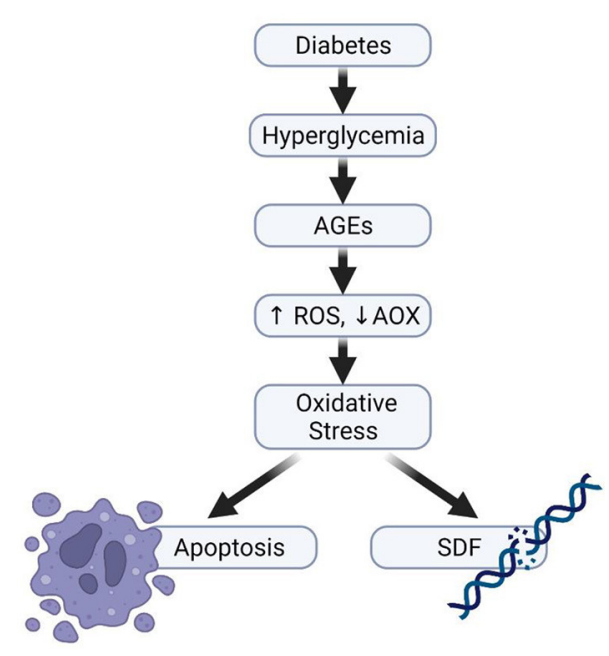

FIGURE 5 | Diabetes and impaired sperm function. Hyperglycaemia can increase the production of advanced glycation end products, thereafter causing imbalance in the ratio of ROS generation and its elimination by antioxidants, thereby resulting in the development of oxidative stress.

consumption allow for substantial free-radical production (157) as the lipids readily provide substrates for oxidation (158). Other factors which contribute toward neuro-susceptibility to OS include, inadequate antioxidant capacities and the availability of redox-catalytic metals $(158,159)$, the same as with spermatozoa.

The independent susceptibility of the brain to OS has been shown in numerous studies. OS is involved in the pathogenesis of depression and in multiple human studies with patients suffering from depression (156). Findings include decreased antioxidant activity, DNA damage, amplified lipid peroxidation and increased ROS production $(156,160)$. An interaction between OS pathways and neurogenesis, the uptake of neurotransmitters and neuroinflammation have additionally been suggested (157). This indicates a connection between OS and depression, as the pathogenesis of this disorder involves neuroinflammation and altered neurotransmitter activity. Defective antioxidant capacities and elevated ROS concentrations have been reported in several studies of schizophrenic patients (157). OS contributes to the pathogenesis of schizophrenia through its effect on neuronal excitability and mitochondrial signaling, factors which impart negative influences on neurons and ultimately promote the development of schizophrenia (161). Similar findings have been implicated in the pathogenesis of bipolar disorder, including the involvement of elevated free radicals such as $\mathrm{NO}$, as well as lipid peroxidation and altered antioxidant levels $(157,162)$.

Psychological stress and anxiety have been shown in various studies to affect male fertility, as well as in the SURRG laboratory (163). The activation of the hypothalamic-pituitaryadrenal axis during stress and anxiety can affect the release of the Gonadotropin Releasing Hormone (GnRH), which can decrease the production of LH, FSH and therefore the release of testosterone (164). In addition, increased psychological stress has been shown to decrease seminal volume, even in healthy individuals (165). The role of $\mathrm{NO}^{\bullet}$ in anxiety has not yet been fully elucidated. However, in a study performed on male mice lacking the gene that encodes for $\mathrm{NO}^{\bullet}$ synthase 1 , these mice were found to have abnormal anxiety levels compared to their counterparts $(166,167)$. In addition, $\mathrm{NO}^{\bullet}$ levels in seminal plasma were shown to be elevated in individuals who scored higher on the State Anxiety Index questionnaire (168). Psychological disorders such as Alzheimer's disease have been shown to cause oxidative damage to glycolytic enzymes as well as enzymes involved in the tricarboxylic cycle during glucose metabolism, thereby affective ATP biogenesis (169). These changes can cause a cascade of oxidative damage that can systemically make its way to the male reproductive system, thereby affecting fertility.

\section{DISCUSSION AND CONCLUSION}

Scientific evidences within and outside the SURRG over the years have revealed that free radicals are neither exclusively beneficial nor exclusively detrimental to the male reproductive functions. Indeed, Redox equilibrium is important for the maintenance of various vital aspects of sperm functionality. However, an imbalance in the generation and elimination of ROS causes impairment in sperm qualities, attributable to oxidative damage due to their limited antioxidant capacity and cell membrane rich in PUFAs. At pathological level, ROS becomes highly reactive, causing substantial damage to various cellular biomolecules such as nucleic acids, proteins and lipids (41). The subsequent series of adverse events include loss of membrane integrity, mitochondrial dysfunction, impaired sperm motility as well as DNA damage and apoptosis resulting in damage of cellular components and pathogenesis of reproductive diseases and infertility (23).

Thus, information obtained from the assessment of OS status could be of great importance in enhancing clinical decision making. However, OS profiling is predominantly used for research settings and is not yet integrated into routine assessment of male infertility. This is primarily due to the lack of universal standards and norms in addition to the assay complexity and high costs (170-173). There is, therefore, a definite need to develop a robust assay that should be simple, validated and easily performed to allow OS screening in a routine andrology laboratories. Further work is also needed to establish cut-off values for the OS key players with sufficient sensitivity and specificity to be clinically useful in the differentiation between fertile and infertile men.

Interestingly, we have established statistical correlations between conventional semen parameters obtained with CASA and a set of OS and membrane lipid peroxidation variables showing that the rapid progressive motility is a valuable sensitive indicator of lipid peroxidation that could be affected, prior to any detectable deterioration in other sperm motion characteristics. Furthermore, the observed inverse relationship between intracellular sperm $\mathrm{O}_{2}^{-} \bullet$ levels and VAP is important in advancing our understanding of the possible role of free radicals in constraining the actual rate of sperm-forward movement 
within the female reproductive tract, which is vital for successful fertilization. These scientific revelations complement those of previous investigators and contribute, additional evidence, with respect to the significance of detailed CASA motility, velocity and kinematic parameters in cementing the relationship between conventional semen analysis and the oxidative status (107).

On the contrary, physiological or homeostatic level of ROS is involved in the activation of intracellular pathways responsible for spermatozoa maturation, capacitation, hyperactivation, acrosomal reaction, chemotactic processes, formation of the mitochondrial capsule and condensation of sperm DNA as well as fusion with the female gamete to ensure fertilization.

The relationship between infertility and potential mechanisms involved in the pathophysiology of various systemic diseases such as insulin resistance, obesity, hypertension, certain mental disorder as well as prolonged ejaculatory abstinence period have also implicated ROS, thereby causing OS induced male infertility in most of these conditions. Kasman et al. (16) have also reported that infertile men had a higher risk of incident for hypertension, diabetes, hyperlipidemia and heart disease regardless of race, region or socioeconomic status. Using animal studies, we have also reported the association between obesityinduced hypertension and male infertility. Obese-hypertensive rats presented with increased levels of serum inflammatory cytokines when compared with control (130). Our studies on the effects of long-term obesity on male reproductive functions suggested that the instigator of the molecular and proteomic modifications includes: an increase in the production of ROS, elevated stress proteins levels and higher levels of redox and inflammatory proteins. Further proteomic analysis of the epididymis and sperm revealed that proteins essential in metabolism, ROS production, stress, inflammation and in the regulation of reproductive function were adversely affected (137). Studies have shown that diabetes, both type I and type II induce

\section{REFERENCES}

1. World Health Organization. WHO Fact Sheet on Infertility. (2021). Available online at: https://journals.lww.com/grh/fulltext/2021/01010/who fact_sheet_on_infertility.1.aspx (accessed October 10, 2021).

2. Kumar N, Singh A. Trends of male factor infertility, an important cause of infertility: a review of literature. J Hum Reprod Sci. (2015) 8:1916. doi: 10.4103/0974-1208.170370

3. World Health Organization. WHO Laboratory Manual for the Examination and Processing of Human Semen, 5th ed. WHO Press (2010).

4. Sharlip ID, Jarow JP, Belker AM, Lipshultz LI, Sigman M, Thomas AJ, et al. Best practice policies for male infertility. Fertil Steril. (2002) 77:87382. doi: 10.1016/S0015-0282(02)03105-9

5. Ghuman N, Ramalingam M. Male infertility. Obs Gynaecol Reprod Med. (2018) 28:7-14. doi: 10.1016/j.ogrm.2017.10.007

6. Sengupta P, Borges E, Dutta S, Krajewska-Kulak E. Decline in sperm count in European men during the past 50 years. Hum Exp Toxicol. (2018) 37:24755. doi: $10.1177 / 0960327117703690$

7. De Jonge C, Barratt CLR. The present crisis in male reproductive health: an urgent need for a political, social, research roadmap. Andrology. (2019) 7:762-8. doi: 10.1111/andr.12673

8. Bahri H, Ben Khalifa M, Ben Rhouma M, Abidi Z, Abbassi E, Ben Rhouma K, et al. Decline in semen quality of North African men: a retrospective study of 20,958 sperm analyses of men from different subtle molecular changes that are essential for sperm quality and function, but a follow up study by our team projected that the adverse effects caused by diabetes mellitus can partly be explained through the impact of OS, caused by the inequality between ROS production and antioxidant defense mechanisms (152).

On the other hand, psychological disorders have been associated with increased $\mathrm{NO}^{\bullet}$ levels and oxidative damage to glycolytic enzymes as well as enzymes involved in the tricarboxylic cycle during glucose metabolism, thereby affecting ATP biogenesis (169). These changes can cause a cascade of oxidative damage that can systemically make its way to the male reproductive system, thereby causing infertility. Deducing from the above findings, it can be suggested that hypertension, obesity, insulin resistance, certain mental disorder and prolonged ejaculatory abstinence period impairs male fertility through increase in the formation of ROS and a subsequent decrease in antioxidant activities, which consequently lead to OS.

\section{AUTHOR CONTRIBUTIONS}

BA: designed the outline of the manuscript, writing, and editing. TO: contributed to the study design, writing, and editing. BS: writing and editing. NL, YR, and PO: writing. SD: helped with the study design, supervised the team, and reviewed the final version of the manuscript. All authors contributed to the article and approved the submitted version.

\section{FUNDING}

This work was supported in part by the Al Jalila Foundation.

\section{ACKNOWLEDGMENTS}

Figures in the manuscript were created on BioRender.com.
North African countries tested in Tunisia over a period of 6 years (2013-2018). Ann Hum Biol. (2021) 48:350-9. doi: 10.1080/03014460.2021. 1957501

9. Rosa-Villagrán L, Barrera N, Montes J, Riso C, Sapiro R. Decline of semen quality over the last 30 years in Uruguay. Basic Clin Androl. (2021) 31:8. doi: 10.1186/s12610-021-00128-6

10. Lalinde-Acevedo PC, Jose Manuel Mayorga-Torres B, Agarwal A, Du Plessis SS, Ahmad G, Cadavid ÁP, et al. Physically active men show better semen parameters than their sedentary counterparts. Int J Fertil Steril. (2017) 11:156-65. doi: 10.22074/ijfs.2017.4881

11. Durairajanayagam D. Lifestyle causes of male infertility. Arab J Urol. (2018) 16:10-20. doi: 10.1016/j.aju.2017.12.004

12. Martins AD, Majzoub A, Agawal A. Metabolic syndrome and male fertility. World J Men's Heal Heal. (2019) 37:113-27. doi: 10.5534/wjmh.180055

13. Muhammad H, Shah AA, Nabi G, Farooqi N. Male infertility: etiological factors. J Toxicol Sci. (2015) 7:95-103.

14. Ilacqua A, Izzo G, Emerenziani GP, Baldari C, Aversa A. Lifestyle and fertility: The influence of stress and quality of life on male fertility. Reprod Biol Endocrinol. (2018) 16:115. doi: 10.1186/s12958-018-0436-9

15. Abbasihormozi S, Babapour V, Naslji AN. Stress hormone and oxidative stress biomarkers link obesity and diabetes with reduced fertility potential. Cell J. (2019) 21:307-13. doi: 10.22074/cellj.2019.6339

16. Kasman AM, Li S, Luke B, Sutcliffe AG, Pacey AA, Eisenberg ML. Male infertility and future cardiometabolic health: does the 
association vary by sociodemographic factors? Urology. 133:121-8. doi: 10.1016/j.urology.2019.06.041

17. Cabler S, Agarwal A, Flint M, Du Plessis SS. Obesity: modern man's fertility nemesis. Asian J Androl. (2010) 12:480-9. doi: 10.1038/aja.2010.38

18. Du Plessis SS, Cabler S, McAlister DA, Sabanegh E, Agarwal A. The effect of obesity on sperm disorders and male infertility. Nat Rev Urol. (2010) 7:153-61. doi: 10.1038/nrurol.2010.6

19. Omolaoye T, Windvogel S, du Plessis S. Testicular oxidative stress and apoptosis status in streptozotocin-induced diabetic rats after treatment with rooibos (Aspalathus linearis), honeybush (Cyclopia intermedia), and sutherlandia (Lessertia frutescens) infusions. Asian Pacific J Reprod. (2021) 10:11-20. doi: 10.4103/2305-0500.321125

20. Palmer NO, Bakos HW, Owens JA, Setchell BP, Lane M. Diet and exercise in an obese mouse fed a high-fat diet improve metabolic health and reverse perturbed sperm function. Am J Physiol Endocrinol Metab. (2012) 302:76880. doi: 10.1152/ajpendo.00401.2011

21. Mayorga-Torres BJM, Camargo M, Cadavid P, du Plessis SS, Cardona Maya WD. Are oxidative stress markers associated with unexplained male infertility? Andrologia. (2017) 49:e12659. doi: 10.1111/and.12659

22. Alahmar A. Role of oxidative stress in male infertility: An updated review. $J$ Hum Reprod Sci. (2019) 12:4-18. doi: 10.4103/jhrs.JHRS_150_18

23. Ritchie C, Ko EY. Oxidative stress in the pathophysiology of male infertility. Andrologia. (2021) 53:e13581. doi: 10.1111/and.13581

24. Kurkowska W, Bogacz A, Janiszewska M, Gabryś E, Tiszler M, Bellanti F, et al. Oxidative stress is associated with reduced sperm motility in normal semen. Am J Mens Health. (2020) 14. doi: 10.1177/1557988320939731

25. Kothari S, Thompson A, Agarwal A, du Plessis SS. Free radicals: their beneficial and detrimental effects on sperm function. Indian J Exp Biol. (2010) 48:425-35.

26. Du Plessis SS, Agarwal A, Halabi J, Tvrda E. Contemporary evidence on the physiological role of reactive oxygen species in human sperm function. $J$ Assist Reprod Genet. (2015) 32:509-20. doi: 10.1007/s10815-014-0425-7

27. Lampiao F. Measurement of Free Radicals and Their Effects on Human Spermatozoa. Stellenbosch University (2006).

28. Pahune PP, Choudhari AR, Muley PA. The total antioxidant power of semen and its correlation with the fertility potential of human male subjects. J Clin Diagnostic Res. (2013) 7:991-5. doi: 10.7860/JCDR/2013/4974.3040

29. Gosalvez J, Tvrda E, Agarwal A. Free radical and superoxide reactivity detection in semen quality assessment: past, present, and future. $J$ Assist Reprod Genet. (2017) 34:697-707. doi: 10.1007/s10815-017-0912-8

30. Mahanta R, Gogoi A, Chaudhury PNB, Roy S, Bhattacharyya IK, Sharma P. Association of oxidative stress biomarkers and antioxidant enzymatic activity in male infertility of North-East India. J Obstet Gynecol India. (2012) 62:546-50. doi: 10.1007/s13224-011-0070-3

31. Beers RF, Sizer IW. A spectrophotometric method for measuring the breakdown of hydrogen peroxide by catalase. J Biol Chem. (1952) 195:13340. doi: 10.1016/S0021-9258(19)50881-X

32. Baumber J, Ball BA. Determination of glutathione peroxidase and superoxide dismutase-like activities in equine spermatozoa, seminal plasma, reproductive tissues. Am J Vet Res. (2005) 66:1415-9. doi: 10.2460/ajvr.2005.66.1415

33. Tsikas D. Assessment of lipid peroxidation by measuring malondialdehyde (MDA) and relatives in biological samples: analytical and biological challenges. Anal Biochem. (2017) 524:13-30. doi: 10.1016/j.ab.2016.10.021

34. Praticò D, Rokach J, Lawson J, FitzGerald GA. F2-isoprostanes as indices of lipid peroxidation in inflammatory diseases. Chem Phys Lipids. (2004) 128:165-71. doi: 10.1016/j.chemphyslip.2003.09.012

35. Janicka M, Kot-Wasik A, Kot J, Namieśnik J. Isoprostanes-biomarkers of lipid peroxidation: their utility in evaluating oxidative stress and analysis. Int J Mol Sci. (2010) 11:4631-59. doi: 10.3390/ijms11114631

36. Gupta S, Finelli R, Agarwal A, Henkel R. Total antioxidant capacityrelevance, methods and clinical implications. Andrologia. (2021) 53:e13624. doi: 10.1111/and.13624

37. Ko EY, Sabanegh ES, Agarwal A. Male infertility testing: reactive oxygen species and antioxidant capacity. Fertil Steril. (2014) 102:151827. doi: 10.1016/j.fertnstert.2014.10.020

38. Agarwal A, Sharma R, Roychoudhury S, Du Plessis S, Sabanegh E. MiOXSYS: a novel method of measuring oxidation reduction potential in semen and seminal plasma. Fertil Steril. (2016) 106:566-73.e10. doi: 10.1016/j.fertnstert.2016.05.013

39. Homa ST, Vassiliou AM, Stone J, Killeen AP, Dawkins A, Xie J, et al. A comparison between two assays for measuring seminal oxidative stress and their relationship with sperm DNA fragmentation and semen parameters. Genes. (2019) 10:236. doi: 10.3390/genes10030236

40. Agarwal A, Allamaneni SSR, Said TM. Chemiluminescence technique for measuring reactive oxygen species. Reprod Biomed Online. (2004) 9:4668. doi: 10.1016/S1472-6483(10)61284-9

41. Benjamin D, Sharma RK, Moazzam A, Agarwal A. Methods for the Detection of ROS in Human Sperm Samples. Stud Men's Heal Fertil. (2012). 257-273. doi: 10.1007/978-1-61779-776-7_13

42. Aitken RJ, Buckingham DW, West KM. Reactive oxygen species and human spermatozoa: analysis of the cellular mechanisms involved in luminol- and lucigenin-dependent chemiluminescence. J Cell Physiol. (1992) 151:46677. doi: 10.1002/jcp.1041510305

43. Khan P, Idrees D, Moxley MA, Corbett JA, Ahmad F, Von Figura G, et al. Luminol-based chemiluminescent signals: clinical and non-clinical application and future uses. Appl Biochem Biotechnol. (2014) 173:33355. doi: 10.1007/s12010-014-0850-1

44. Kobayashi H, Gil-Guzman E, Mahran AM, Sharma RK, Nelson DR, Thomas AJ, et al. Quality control of reactive oxygen species measurement by luminol-dependent chemiluminescence assay. J Androl. (2001) 22:568-74. doi: 10.1002/(ISSN)1939-4640

45. Lampiao F, Strijdom H, Du Plessis SS. Direct nitric oxide measurement in human spermatozoa: flow cytometric analysis using the fluorescent probe, diaminofluorescein. Int $J$ Androl. (2006) 29:564-7. doi: 10.1111/j.1365-2605.2006.00695.x

46. Hamada A, Sharma R, Du Plessis SS, Willard B, Yadav SP, Sabanegh E, et al. Two-dimensional differential in-gel electrophoresis-based proteomics of male gametes in relation to oxidative stress. Fertil Steril. (2013) 99:121626.e2. doi: 10.1016/j.fertnstert.2012.11.046

47. Mupfiga C, Fisher D, Kruger T, Henkel R. The relationship between seminal leukocytes, oxidative status in the ejaculate, and apoptotic markers in human spermatozoa. Syst Biol Reprod Med. (2013) 59:30411. doi: 10.3109/19396368.2013.821540

48. Marques M, Sousa AP, Paiva A, Almeida-Santos T, Ramalho-Santos J. Low amounts of mitochondrial reactive oxygen species define human sperm quality. Reproduction. (2014) 147:817-24. doi: 10.1530/REP-13-0644

49. Lackner JE, Agarwal A, Mahfouz R, du Plessis SS, Schatzl G. The association between leukocytes and sperm quality is concentration dependent. Reprod Biol Endocrinol. (2010) 8:1-6. doi: 10.1186/1477-7827-8-12

50. Rengan AK, Agarwal A, van der Linde $M$, du Plessis SS. An investigation of excess residual cytoplasm in human spermatozoa and its distinction from the cytoplasmic droplet. Reprod Biol Endocrinol. (2012) 10:92. doi: 10.1186/1477-7827-10-92

51. de Mola JRL, Gindlesperger C, Gindlesperger V, Glavan D, Arredondo F, Liu J. The relationship between leukospermia, sperm morphology and the acrosome reaction in infertile men. Fertil Steril. (2004) 82:S85: 418. doi: 10.1016/j.fertnstert.2004.07.216

52. Sanocka-Maciejewska D, Ciupińska M, Kurpisz M. Bacterial infection and semen quality. J Reprod Immunol. (2005) 67:51-6. doi: 10.1016/j.jri.2005. 06.003

53. Domes T, Lo KC, Grober ED, Mullen JBM, Mazzulli T, Jarvi K. The incidence and effect of bacteriospermia and elevated seminal leukocytes on semen parameters. Fertil Steril. (2012) 97:1050-5. doi: 10.1016/j.fertnstert.2012.01.124

54. Flint M, du Plessis SS, Menkveld R. Revisiting the assessment of semen viscosity and its relationship to leucocytospermia. Andrologia. (2014) 46:837-41. doi: 10.1111/and.12157

55. Cocuzza M, Sikka SC, Athayde KS, Agarwal A. Clinical relevance of oxidative stress and sperm chromation damage in male infertility: An evidence based analysis. Int Braz J Urol. (2007) 33:603-21. doi: 10.1590/S1677-55382007000500002

56. Fraczek M, Kurpisz M. Mechanisms of the harmful effects of bacterial semen infection on ejaculated human spermatozoa: potential inflammatory markers in semen. Folia Histochem Cytobiol. (2015)53:201-17. doi: 10.5603/fhc.a2015.0019 
57. Fraczek M, Szumala-Kakol A, Jedrzejczak P, Kamieniczna M, Kurpisz M. Bacteria trigger oxygen radical release and sperm lipid peroxidation in in vitro model of semen inflammation. Fertil Steril. (2007) 88:107685. doi: 10.1016/j.fertnstert.2006.12.025

58. Koppers AJ, De Iuliis GN, Finnie JM, McLaughlin EA, Aitken RJ. Significance of mitochondrial reactive oxygen species in the generation of oxidative stress in spermatozoa. J Clin Endocrinol Metab. (2008) 93:3199207. doi: 10.1210/jc.2007-2616

59. Gualtieri R, Kalthur G, Barbato V, Longobardi S, Di Rella F, Adiga SK, et al. Sperm oxidative stress during in vitro manipulation and its effects on sperm function and embryo development. Antioxidants. (2021) 10:1025. doi: 10.3390/antiox 10071025

60. Finelli R, Leisegang K, Kandil H, Agarwal A. Oxidative Stress: a comprehensive review of biochemical, molecular, and genetic aspects in the pathogenesis and management of varicocele. World J Mens Health. (2022) 40:87-103. doi: 10.5534/wjmh.210153

61. Jensen CFS, Østergren P, Dupree JM, Ohl DA, Sønksen J, Fode M. Varicocele and male infertility. Nat Rev Urol. (2017) 14:52333. doi: 10.1038/nrurol.2017.98

62. Gorelick JI, Goldstein M. Loss of fertility in men with varicocele. Fertil Steril. (1993) 59:613-6. doi: 10.1016/S0015-0282(16)55809-9

63. Allamaneni SSR, Naughton CK, Sharma RK, Thomas AJ, Agarwal A. Increased seminal reactive oxygen species levels in patients with varicoceles correlate with varicocele grade but not with testis size. Fertil Steril. (2004) 82:1684-6. doi: 10.1016/j.fertnstert.2004.04.071

64. Cocuzza M, Athayde KS, Alvarenga C, Srougi M, Hallak J. Grade 3 varicocele in fertile men: a different entity. J Urol. (2012) 187:13638. doi: 10.1016/j.juro.2011.11.114

65. Mostafa T, Anis T, El Nashar A, Imam H, Osman I. Seminal plasma reactive oxygen species-antioxidants relationship with varicocele grade. Andrologia. (2012) 44:66-9. doi: 10.1111/j.1439-0272.2010.01111.x

66. Chen SS, Huang WJ, Chang LS, Wei YH. 8-Hydroxy-2' deoxyguanosine in leukocyte DNA of spermatic vein as a biomarker of oxidative stress in patients with varicocele. J Urol. (2004) 172:1418-21. doi: 10.1097/01.ju.0000138344.56941.b1

67. Yuan R, Zhuo H, Cao D, Wei Q. Efficacy and safety of varicocelectomies: a meta-analysis. Syst Biol Reprod Med. (2017) 63:120-9. doi: 10.1080/19396368.2016.1265161

68. Zaazaa A, Adel A, Fahmy I, Elkhiat Y, Awaad AA, Mostafa T. Effect of varicocelectomy and/or mast cells stabilizer on sperm DNA fragmentation in infertile patients with varicocele. Andrology. (2018) 6:14650. doi: 10.1111/andr.12445

69. Wang Q, Yu Y, Liu Y, Wang L. Outcome of varicocelectomy on different degrees of total motile sperm count: a systematic review and meta-analysis. Syst Biol Reprod Med. (2019) 65:430-6. doi: 10.1080/19396368.2019.1655813

70. Esteves SC, Santi D, Simoni M. An update on clinical and surgical interventions to reduce sperm DNA fragmentation in infertile men. Andrology. (2020) 8:53-81. doi: 10.1111/andr.12724

71. Omolaoye TS, El Shahawy O, Skosana BT, Boillat T, Loney T, du Plessis SS. The mutagenic effect of tobacco smoke on male fertility. Environ Sci Pollut Res. (2021). doi: 10.1007/s11356-021-16331-x

72. Das SK, Vasudevan DM. Alcohol-induced oxidative stress. Life Sci. (2007) 81:177-87. doi: 10.1016/j.lfs.2007.05.005

73. Gautam R, Singh KV, Nirala J, Murmu NN, Meena R, Rajamani P. Oxidative stress-mediated alterations on sperm parameters in male Wistar rats exposed to $3 \mathrm{G}$ mobile phone radiation. Andrologia. (2019) 51:e13201. doi: 10.1111/and.13201

74. Baker MA, Aitken RJ. The importance of redox regulated pathways in sperm cell biology. Mol Cell Endocrinol. (2004) 216:47-54. doi: 10.1016/j.mce.2003. 10.068

75. de Lamirande E, Cagnon C. Human sperm hyperactivation and capacitation as parts of an oxidative process. Free Radic Biol Med. (1993) 14:15766. doi: 10.1016/0891-5849(93)90006-G

76. Huang Z, Danshina PV, Mohr K, Qu W, Goodson SG, O'Connell $\mathrm{TM}$, et al. Sperm function, protein phosphorylation, and metabolism differ in mice lacking successive sperm-specific glycolytic enzymes. Biol Reprod. (2017) 97:586-97. doi: 10.1093/biolre/ iox 103
77. Griveau JE, Renard P, Le Lannou D. An in vitro promoting role for hydrogen peroxide in human sperm capacitation. Int J Androl. (1994) 17:423-36. doi: 10.1111/j.1365-2605.1994.tb01260.x

78. Chang MC. The meaning of sperm capacitation a historical perspective. $J$ Androl. (1984) 5:45-50. doi: 10.1002/j.1939-4640.1984.tb00775.x

79. O'Flaherty C, De Lamirande E, Gagnon C. Reactive oxygen species modulate independent protein phosphorylation pathways during human sperm capacitation. Free Radic Biol Med. (2006) 40:1045-55. doi: 10.1016/j.freeradbiomed.2005. 10.055

80. Hindley A, Kolch W. Extracellular signal regulated kinase (ERK)/mitogen activated protein kinase (MAPK)-independent functions of raf kinases. J Cell Sci. (2002) 115:1575-81. doi: 10.1242/jcs.115.8.1575

81. Naz RK, Rajesh PB. Role of tyrosine phosphorylation in sperm capacitation/acrosome reaction. Reprod Biol Endocrinol. (2004) 2:75. doi: 10.1186/1477-7827-2-75

82. Breitbart H, Rubinstein S, Lax Y. Regulatory mechanisms in acrosomal exocytosis. Rev Reprod. (1997) 2:165-74. doi: 10.1530/ror.0.0020165

83. Anifandis G, Messini C, Dafopoulos K, Sotiriou S, Messinis I. Molecular and cellular mechanisms of sperm-oocyte interactions opinions relative to in vitro fertilization (IVF). Int J Mol Sci. (2014) 15:12972-97. doi: 10.3390/ijms150712972

84. Van der Horst G, du PS. Not just the marriage of Figaro: but the marriage of WHO/ESHRE semen analysis criteria with sperm functionality. Postepy Androl Online. (2017) 4:6-21.

85. Liguori L, de Lamirande E, Minelli A, Gagnon C. Various protein kinases regulate human sperm acrosome reaction and the associated phosphorylation of Tyr residues and of the Thr-Glu-Tyr motif. Mol Hum Reprod. (2005) 11:211-21. doi: 10.1093/molehr/gah154

86. De Lamirande E, Jiang $H$, Zini A, Kodama H, Gagnon C. Reactive oxygen species and sperm physiology. Rev Reprod. (1997) 2:48-54. doi: 10.1530/ror.0.0020048

87. Padron OF, Lynne CM, Brackett NL, Thomas AJ, Sharma RK, Agarwal A. Seminal reactive oxygen species and sperm motility and morphology in men with spinal cord injury. Fertil Steril. (1997) 67:1115-20. doi: 10.1016/S0015-0282(97)81448-3

88. Agarwal A, Mulgund A, Sharma R, Sabanegh E. Mechanisms of oligozoospermia: an oxidative stress perspective. Syst Biol Reprod Med. (2014) 60:206-16. doi: 10.3109/19396368.2014.918675

89. Oborna I, Fingerova H, Novotny J, Brezinova J, Svobodova M, Aziz $\mathrm{N}$. Reactive oxygen species in human semen in relation to leukocyte contamination. Biomed Pap. (2009) 153:53-7. doi: 10.5507/bp.2009.009

90. Ayala A, Muñoz MF, Argüelles S. Lipid peroxidation: production, metabolism, and signaling mechanisms of malondialdehyde and 4-hydroxy2-nonenal. Oxid Med Cell Longev. (2014) 1-31. doi: 10.1155/2014/360438

91. Collodel G, Moretti E, Micheli L, Menchiari A, Moltoni L, Cerretani D. Semen characteristics and malondialdehyde levels in men with different reproductive problems. Andrology. (2015) 3:280-6. doi: 10.1111/andr.297

92. Epe B, Ballmaier D, Roussyn I, Briviba K, Sies H. DNA damage by peroxynitrite characterized with DNA repair enzymes. Nucleic Acids Res. (1996) 24:4105-10. doi: 10.1093/nar/24.21.4105

93. Zribi N, Chakroun NF, Elleuch H, Abdallah FB, Ben Hamida AS, Gargouri J, et al. Sperm DNA fragmentation and oxidation are independent of malondialdheyde. Reprod Biol Endocrinol. (2011) 9:1-8.. doi: 10.1186/1477-7827-9-47

94. Iommiello VM, Albani E, Di Rosa A, Marras A, Menduni F, Morreale G, et al. Ejaculate oxidative stress is related with sperm DNA fragmentation and round cells. Int J Endocrinol. (2015) 1-6. doi: 10.1155/2015/321901

95. Vaughan DA, Tirado E, Garcia D, Datta V, Sakkas D. DNA fragmentation of sperm: a radical examination of the contribution of oxidative stress and age in 16945 semen samples. Hum Reprod. (2020) 35:218896. doi: 10.1093/humrep/deaa159

96. Elbardisi H, Finelli R, Agarwal A, Majzoub A, Henkel R, Arafa M. Predictive value of oxidative stress testing in semen for sperm DNA fragmentation assessed by sperm chromatin dispersion test. Andrology. (2020) 8:6107. doi: 10.1111/andr.12743

97. Mahfouz RZ, du Plessis SS, Aziz N, Sharma R, Sabanegh E, Agarwal A. Sperm viability, apoptosis, and intracellular reactive oxygen species 
levels in human spermatozoa before and after induction of oxidative stress. Fertil Steril. (2010) 93:814-21. doi: 10.1016/j.fertnstert.2008. 10.068

98. Agarwal A, Said TM. Role of sperm chromatin abnormalities and DNA damage in male infertility. Hum Reprod Update. (2003) 9:33145. doi: 10.1093/humupd/dmg027

99. Yüce A, Türk G, Çeribaşi S, Sönmez M, Çiftçi M, Güvenç M. Effects of cinnamon (Cinnamomum zeylanicum) bark oil on testicular antioxidant values, apoptotic germ cell and sperm quality. Andrologia. (2013) 45:24855. doi: 10.1111/and.12000

100. Bisht S, Faiq M, Tolahunase M, Dada R. Oxidative stress and male infertility. Nat Rev Urol. (2017) 14:470-85. doi: 10.1038/nrurol.2017.69

101. Barik G, Chaturvedula L, Bobby Z. Role of oxidative stress and antioxidants in male infertility: an interventional study. J Hum Reprod Sci. (2019) 12:2049. doi: 10.4103/jhrs.JHRS_135_18

102. De Luca MN, Colone M, Gambioli R, Stringaro A, Unfer V. Oxidative stress and male fertility: role of antioxidants and inositols. Antioxidants. (2021) 14. doi: 10.3390 /antiox 10081283

103. Ammar O, Mehdi M, Muratori M. Teratozoospermia: its association with sperm DNA defects, apoptotic alterations, oxidative stress. Andrology. (2020) 8:1095-106. doi: 10.1111/andr.12778

104. Aziz N, Saleh RA, Sharma RK, Lewis-Jones I, Esfandiari N, Thomas AJ, et al. Novel association between sperm reactive oxygen species production, sperm morphological defects, and the sperm deformity index. Fertil Steril. (2004) 81:349-54. doi: 10.1016/j.fertnstert.2003.06.026

105. Dobrakowski M, Kasperczyk S, Horak S, Chyra-Jach D, Birkner E, Kasperczyk A. Oxidative stress and motility impairment in the semen of fertile males. Andrologia. (2017) 49:1. doi: 10.1111/and.12783

106. Nowicka-bauer K, Nixon B. Molecular changes induced by oxidative stress that impair human sperm motility. Antioxidants. (2020). doi: 10.3390/antiox9020134

107. Ayad BM, Oyeyipo IP, Van der Horst G, Du Plessis SS. Cementing the relationship between conventional advanced semen parameters. Middle East Fertil Soc J. (2021) 9:134. doi: 10.1186/s43043-021-00086-Z

108. WHO. WHO Laboratory Manual for the Examination and Processing of Human Semen 5th ed. WHO Press. (2021).

109. Oxford. Manual on basic semen analysis. ESHRE Monogr. (2002) 137. doi: 10.1093/eshremonographs/2002.2.13

110. Ayad BM, Van der Horst G, Du Plessis SS. Revisiting the relationship between the ejaculatory abstinence period and semen characteristics. Int J Fertil Steril. (2018) 11:238-46. doi: 10.22074/ijfs. 2018.5192

111. Mayorga-Torres BJM, Camargo M, Agarwal A, du Plessis SS, Cadavid ÁP, Cardona Maya WD. Influence of ejaculation frequency on seminal parameters. Reprod Biol Endocrinol. (2015) 13:1-7. doi: 10.1186/s12958-015-0045-9

112. Mayorga-Torres JM, Agarwal A, Roychoudhury S, Cadavid A, CardonaMaya WD. Can a short term of repeated ejaculations affect seminal parameters? J Reprod Infertil. (2016) 17:177-83.

113. Desai NR, Mahfouz R, Sharma R, Gupta S, Agarwal A. Reactive oxygen species levels are independent of sperm concentration, motility, and abstinence in a normal, healthy, proven fertile man: a longitudinal study. Fertil Steril. (2010) 94:1541-3. doi: 10.1016/j.fertnstert.2009.12.041

114. Marshburn PB, Giddings A, Causby S, Matthews ML, Usadi RS, Steuerwald $\mathrm{N}$, et al. Influence of ejaculatory abstinence on seminal total antioxidant capacity and sperm membrane lipid peroxidation. Fertil Steril. (2014) 102:705-10. doi: 10.1016/j.fertnstert.2014.05.039

115. Ayad BM, Van der Horst G, du Plessis SS. Short abstinence: a potential strategy for the improvement of sperm quality. Middle East Fertil Soc J. (2018) 23:37-43. doi: 10.1016/j.mefs.2017.07.005

116. Degirmenci Y, Demirdag E, Guler I, Yildiz S, Erdem M, Erdem A. Impact of the sexual abstinence period on the production of seminal reactive oxygen species in patients undergoing intrauterine insemination: a randomized trial. J Obstet Gynaecol Res. (2020) 46:1133-9. doi: 10.1111/jog.14308

117. Okada FK, Andretta RR, Spaine DM. One day is better than four days of ejaculatory abstinence for sperm function. Reprod Fertil. (2020) 1:110. doi: 10.1530/RAF-20-0018
118. Goss D, Ayad B, Van Der Horst G, Skosana B, Du Plessis SS. Improved sperm motility after $4 \mathrm{~h}$ of ejaculatory abstinence: role of accessory sex gland secretions. Reprod Fertil Dev. (2019) 31:1009-16. doi: 10.1071/RD18135

119. WHO. Hypertension. (2021). Available online at: http://www.who.int/newsroom/fact-sheets/details/hypertension (accessed October 12, 2021).

120. Guo D, Li S, Behr B, Eisenberg ML. Hypertension and male fertility. World J Mens Health. (2017) 35:59-64. doi: 10.5534/wjmh.2017.35.2.59

121. Guo D, Li S, Behr B, Eisenberg M. PD52-12 the impact of hypertension and antihypertensives on semen quality. J Urol. (2015) 193:e117. doi: 10.1016/j.juro.2015.02.1786

122. Breigeiron MK, Lucion AB, Sanvitto GL. Effects of renovascular hypertension on reproductive function in male rats. Life Sci. (2007) 80:1627-34. doi: 10.1016/j.lfs.2007.01.030

123. Muciaccia B, Pensini S, Culasso F, Padula F, Paoli D, Gandini L, et al. Higher clusterin immunolabeling and sperm DNA damage levels in hypertensive men compared with controls. Hum Reprod. (2012) 27:226776. doi: 10.1093/humrep/des 173

124. Shiraishi K, Matsuyama H. Effects of medical comorbidity on male infertility and comorbidity treatment on spermatogenesis. Fertil Steril. (2018) 110:1006-11. doi: 10.1016/j.fertnstert.2018.07.002

125. Danielewicz A, Morze J, Przybyłowicz M, Przybyłowicz KE. Association of the dietary approaches to stop hypertension, physical activity, and their combination with semen quality: a cross-sectional study. Nutrients. (2019) 12:39. doi: $10.3390 /$ nu12010039

126. Cazzaniga W, Capogrosso P, Ventimiglia E, Pederzoli F, Boeri L, Frego N, et al. High blood pressure is a highly prevalent but unrecognised condition in primary infertile men: results of a cross-sectional study. Eur Urol Focus. (2020) 6:178-83. doi: 10.1016/j.euf.2018.07.030

127. Behboudi-Gandevani S, Yarandi RB, Dovom MR, Azizi F, Tehrani FR. The association between male infertility and cardiometabolic disturbances: a population-based study. Int J Endocrinol Metab. (2021) 19:e107418. doi: 10.21203/rs.3.rs-29105/v1

128. Akinyemi AJ, Adedara IA, Thome GR, Morsch VM, Rovani MT, Mujica LKS, et al. Dietary supplementation of ginger and turmeric improves reproductive function in hypertensive male rats. Toxicol Reports. (2015) 2:1357-66. doi: 10.1016/j.toxrep.2015.10.001

129. Akomolafe SF, Olasehinde TA, Oladapo IF, Oyeleye SI. Diet supplemented with chrysophyllum albidum G. don (Sapotaceae) fruit pulp improves reproductive function in hypertensive male rats. Reprod Sci. (2021) 54056. doi: 10.1007/s43032-021-00746-5

130. Manirafasha C, du Plessis SS. The Effects of a Green Rooibos Extract ObesityInduced Insulin Resistant. Stellenbosch University (2019).

131. WHO. Obesity and Overweight. (2021). Available online at: www.who.int/ news-room/fact-sheets/detail/obesity-and-overweight (accessed October 9, 2021).

132. Mu Y, Yin TL, Huang XX, Hu X, Yin L, Yang J. Sulforaphane ameliorates high-fat diet-induced spermatogenic deficiency in mice. Biol Reprod. (2019) 101:223-34. doi: 10.1093/biolre/ioz067

133. Deshpande SS, Nemani H, Pothani S, Balasinor NH. Altered endocrine, cytokine signaling and oxidative stress: a plausible reason for differential changes in testicular cells in diet-induced and genetically-inherited - obesity in adult rats. Reprod Biol. (2019) 19:303-8. doi: 10.1016/j.repbio.2019. 06.005

134. Raad G, Hazzouri M, Bottini S, Trabucchi M, Azoury J, Grandjean V. Paternal obesity: how bad is it for sperm quality and progeny health? Basic Clin Androl. (2017) 27:1-12. doi: 10.1186/s12610-017-0064-9

135. Raad G, Azouri J, Rizk K, Zeidan NS, Azouri J, Grandjean V, et al. Adverse effects of paternal obesity on the motile spermatozoa quality. PLoS ONE. (2019) 14:1-23. doi: 10.1371/journal.pone.0211837

136. Oyeyipo IP, Skosana BT, Everson FP, Strijdom H, du Plessis SS. Highly active antiretroviral therapy alters sperm parameters and testicular antioxidant status in diet-induced obese rats. Toxicol Res. (2018) 34:418. doi: 10.5487/TR.2018.34.1.041

137. Skosana BT, du Plessis SS. An Investigation of Obesity as an Etiology Of Male Infertility In a Rat Model. Stellenbosch University (2021).

138. Deshpande SS, Nemani H, Pothani S, Khambata K, Kumar A, Kallamadi PR, et al. Genetically inherited obesity and high-fat diet-induced obesity 
differentially alter spermatogenesis in adult male rats. Endocrinology. (2019) 160:220-34. doi: 10.1210/en.2018-00569

139. Zhang S, Zhang M, Sun S, Wei X, Chen Y, Zhou P, et al. Moderate calorie restriction ameliorates reproduction via attenuating oxidative stress-induced apoptosis through SIRT1 signaling in obese mice. Ann Transl Med. (2021) 9:933. doi: 10.21037/atm-21-2458

140. Mohammadi Roushandeh A, Salehi I, Mortazavi M. Protective effects of restricted diet and antioxidants on testis tissue in rats fed with high-fat diet. Iran Biomed J. (2015) 19:96-101. doi: 10.6091/ibj.1398.2015

141. Ye J, Luo D, Xu X, Sun M, Su X, Tian Z, et al. Metformin improves fertility in obese males by alleviating oxidative stress-induced blood-testis barrier damage. Oxid Med Cell Longev. (2019) 1-17. doi: 10.1155/2019/9151067

142. Jia YF, Feng Q, Ge ZY, Guo Y, Zhou F, Zhang KS, et al. Obesity impairs male fertility through long-term effects on spermatogenesis. BMC Urol. (2018) 18:1-8. doi: 10.1186/s12894-018-0360-5

143. Taha EA, Sayed SK, Gaber HD, Abdel Hafez HK, Ghandour N, Zahran A, et al. Does being overweight affect seminal variables in fertile men? Reprod Biomed Online. (2016) 33:703-8. doi: 10.1016/j.rbmo.2016.08.023

144. Silink M. Childhood diabetes: a global perspective. Horm Res. (2002) 15. doi: 10.1159/000053304

145. Guariguata L, Whiting DR, Hambleton I, Beagley J, Linnenkamp U, Shaw JE. Global estimates of diabetes prevalence for 2013 and projections for 2035. Diabetes Res Clin Pract. (2014) 103:137-49. doi: 10.1016/j.diabres.2013.11.002

146. Bhattacharya SM, Ghosh M, Nandi N. Diabetes mellitus and abnormalities in semen analysis. J Obstet Gynaecol Res. (2014) 40:167-71. doi: 10.1111/jog.12149

147. Delfino M, Imbrogno N, Elia J, Capogreco F, Mazzilli F. Prevalence of diabetes mellitus in male partners of infertile couples. Minerva Urol Nefrol. (2007) 59:131-5.

148. Mallidis C, Agbaje IM, Rogers DA, Glenn JV, Pringle R, Atkinson $\mathrm{AB}$, et al. Advanced glycation end products accumulate in the reproductive tract of men with diabetes. Int $J$ Androl. (2009) 32:295-305. doi: 10.1111/j.1365-2605.2007.00849.x

149. Roessner C, Paasch U, Kratzsch J, Glander HJ, Grunewald S. Sperm apoptosis signalling in diabetic men. Reprod Biomed Online. (2012) 25:2929. doi: 10.1016/j.rbmo.2012.06.004

150. Zhao Y, Tan Y, Dai J, Li B, Guo L, Cui J, et al. Exacerbation of diabetesinduced testicular apoptosis by zinc deficiency is most likely associated with oxidative stress, p38 MAPK activation, and p53 activation in mice. Toxicol Lett. (2011) 200:100-6. doi: 10.1016/j.toxlet.2010.11.001

151. Shayakhmetova GM, Bondarenko LB, Matvienko AV, Kovalenko VM. Correlation between spermatogenesis disorders and rat testes CYP2E1 mRNA contents under experimental alcoholism or type I diabetes. Adv Med Sci. (2014) 59:183-9. doi: 10.1016/j.advms.2014.03.004

152. Omolaoye TS, Skosana BT, du Plessis SS. Diabetes mellitus- induction: effect of different streptozotocin doses on male reproductive parameters. Acta Histochem. (2018) 120:103-9. doi: 10.1016/j.acthis.2017.12.005

153. Omolaoye TS, Windvogel SL, Du Plessis SS. The effect of rooibos (Aspalathus linearis), Honeybush (Cyclopia intermedia) and Sutherlandia (Lessertia frutescens) on testicular insulin signalling in streptozotocin-induced diabetes in wistar rats. Diabetes Metab Syndr Obes Targets Ther. (2021) 14:126780. doi: 10.2147/DMSO.S285025

154. Tremellen K. Oxidative stress and male infertility: a clinical perspective. Stud Men's Heal Fertil. (2012) 14:325-53. doi: 10.1007/978-1-61779-776-7_16

155. Hassan W, Noreen H, Castro-Gomes V, Mohammadzai I, Batista Teixeira da Rocha J, Landeira-Fernandez J. Association of oxidative stress with psychiatric disorders. Curr Pharm Des. (2016) 22:296074. doi: 10.2174/1381612822666160307145931

156. Ng F, Berk M, Dean O, Bush AI. Oxidative stress in psychiatric disorders: evidence base and therapeutic implications. Int J Neuropsychopharmacol. (2008) 11:851-76. doi: 10.1017/S1461145707008401

157. Salim S. Oxidative stress and psychological disorders. Curr Neuropharmacol. (2014) 12:140-7. doi: 10.2174/1570159X11666131120230309

158. Valko M, Leibfritz D, Moncol J, Cronin MTD, Mazur M, Telser J. Free radicals and antioxidants in normal physiological functions and human disease. Int $J$ Biochem Cell Biol. (2007) 39:44-84. doi: 10.1016/j.biocel.2006.07.001
159. Halliwell B. Oxidative stress and neurodegeneration: where are we now? J Neurochem. (2006) 97:1634-58. doi: 10.1111/j.1471-4159.2006.03907.x

160. Maes M, Galecki P, Chang YS, Berk M. A review on the oxidative and nitrosative stress (O\&NS) pathways in major depression and their possible contribution to the (neuro)degenerative processes in that illness. Prog Neuro Psychopharmacology Biol Psychiatry. (2011) 35:67692. doi: 10.1016/j.pnpbp.2010.05.004

161. Do KQ, Cabungcal JH, Frank A, Steullet P, Cuenod M. Redox dysregulation, neurodevelopment, and schizophrenia. Curr Opin Neurobiol. (2009) 19:22030. doi: 10.1016/j.conb.2009.05.001

162. Andreazza AC, Kauer-Sant'Anna M, Frey BN, Bond DJ, Kapczinski F, Young LT, et al. Oxidative stress markers in bipolar disorder: a meta-analysis. J Affect Disord. (2008) 111:135-44. doi: 10.1016/j.jad.2008.04.013

163. De Jager TAL. Observing the Effects of Anxiety Levels on Male Reproductive Parameters. Stellenbosch University (2019).

164. Whirledge S, Cidlowski JA. Glucocorticoids, stress, and fertility. Minerva Endocrinol. (2010) 35:109-25.

165. Vellani E, Colasante A, Mamazza L, Minasi MG, Greco E, Bevilacqua A. Association of state and trait anxiety to semen quality of in vitro fertilization patients: a controlled study. Fertil Steril. (2013) 99:156572. doi: 10.1016/j.fertnstert.2013.01.098

166. Bilbo SD, Hotchkiss AK, Chiavegatto S, Nelson RJ. Blunted stress responses in delayed type hypersensitivity in mice lacking the neuronal isoform of nitric oxide synthase. J Neuroimmunol. (2003) 140:418. doi: 10.1016/S0165-5728(03)00175-9

167. Pitsikas N. The role of nitric oxide (NO) donors in anxiety. Lights and shadows. Nitric Oxide. (2018) 77:6-11. doi: 10.1016/j.niox.2018. 04.002

168. Eskiocak S, Gozen AS, Taskiran A, Kilic AS, Eskiocak M, Gulen S. Effect of psychological stress on the L-argininenitric oxide pathway and semen quality. Brazilian $J$ Med Biol Res. (2006) 39:581-8. doi: 10.1590/S0100-879X20060005 00003

169. Butterfield DA, Halliwell B. Oxidative stress, dysfunctional glucose metabolism and Alzheimer disease. Nat Rev Neurosci. (2019) 20:14860. doi: 10.1038/s41583-019-0132-6

170. Lamb DJ. Semen analysis in 21 st century medicine: the need for sperm function testing. Asian J Androl. (2010) 12:64-70. doi: 10.1038/aja.2009.4

171. Talwar P, Hayatnagarkar S. Sperm function test. J Hum Reprod Sci. (2015) 8:61-9. doi: 10.4103/0974-1208.158588

172. Van Der Horst G, Du Plessis SS. Not just the marriage of figaro: but the marriage of who/eshre semen analysis criteria with sperm functionality. Postepy Andrologii Online. (2017) 4:6-21. Available online at: https://www. researchgate.net/publication/317167278

173. van der Horst G, Skosana B, Legendre A, Oyeyipo P, du Plessis SS. Cut-off values for normal sperm morphology and toxicology for automated analysis of rat sperm morphology and morphometry. Biotech Histochem. (2018) 93:49-58. doi: 10.1080/10520295.2017. 1380842

Conflict of Interest: The authors declare that the research was conducted in the absence of any commercial or financial relationships that could be construed as a potential conflict of interest.

Publisher's Note: All claims expressed in this article are solely those of the authors and do not necessarily represent those of their affiliated organizations, or those of the publisher, the editors and the reviewers. Any product that may be evaluated in this article, or claim that may be made by its manufacturer, is not guaranteed or endorsed by the publisher.

Copyright (๑) 2022 Ayad, Omolaoye, Louw, Ramsunder, Skosana, Oyeipo and Du Plessis. This is an open-access article distributed under the terms of the Creative Commons Attribution License (CC BY). The use, distribution or reproduction in other forums is permitted, provided the original author(s) and the copyright owner(s) are credited and that the original publication in this journal is cited, in accordance with accepted academic practice. No use, distribution or reproduction is permitted which does not comply with these terms. 